\title{
Effects of L-Theanine on Cognitive Function in Middle-Aged and Older Subjects: A Randomized Placebo-Controlled Study
}

\author{
Yoshitake Baba, ${ }^{1}$ Shun Inagaki, ${ }^{1}$ Sae Nakagawa, ${ }^{1}$ Toshiyuki Kaneko, ${ }^{2}$ \\ Makoto Kobayashi, ${ }^{1}$ and Takanobu Takihara ${ }^{1}$ \\ ${ }^{I}$ Central Research Institute, ITO EN, LTD., Shizuoka, Japan. \\ ${ }^{2}$ Tokyo Skytree Station Medical Clinic, Tokyo, Japan.
}

\begin{abstract}
L-theanine ( $\gamma$-glutamylethylamide), an amino acid in green tea, has been shown to affect brain functions by relieving stress disorders, improving mood, and maintaining normal sleep. However, the cognitive functions for which theanine is effective are unclear. This study aimed to clarify which cognitive functions are positively affected by intake of L-theanine. A double-blind, randomized, placebo-controlled study was conducted. The subjects were Japanese men and women aged 50-69 years. Mini Mental State Examination-Japanese version score was 24 or higher. Cognitrax was used as a test battery for cognitive function. Evaluations were performed before the intervention, after a single dose of L-theanine, and after 12 weeks of regular intake. The single dose of L-theanine reduced the reaction time to attention tasks (Stroop test, Part 1), and it increased the number of correct answers and decreased the number of omission errors in working memory tasks (4-Part continuous performance test, Part 4). In conclusion, our study indicated that L-theanine may contribute to improving attention, thus enhancing working memory and executive functions. Clinical Trial No.: UMIN000033812.
\end{abstract}

KEYWORDS: • attention • brain function • Cognitrax • executive function • green tea amino acid • working memory

\section{INTRODUCTION}

$\mathbf{l}$ -THEANINE IS A nonproteinogenic amino acid contained in green tea ${ }^{1}$ and mushrooms. ${ }^{2}$ Among the different tea varieties in Japan, gyokuro and matcha contain more L-theanine than sencha. ${ }^{3}$ L-theanine affects brain functions. ${ }^{4}$ Studies in mice indicate that it improves behavior under stress conditions, ${ }^{5}$ suppresses deterioration of learning ability under social stress, ${ }^{6}$ and improves memory impairment. ${ }^{7}$

The epidemiologic Nakajima ${ }^{8}$ and Tsurugaya studies ${ }^{9}$ in Japan indicated that green tea may improve age-related cognitive impairment. In addition, the Hisayama study warned about a recent increase in the prevalence of Alzheimer's disease $(\mathrm{AD}){ }^{10,11}$ Prevention of $\mathrm{AD}$ is an important problem worldwide, and it is necessary to seek a solution.

Green tea contains several substances that affect cognitive function, including caffeine, ${ }^{12,13}$ L-theanine, ${ }^{7,14}$ and catechin. ${ }^{15,16}$ Caffeine transiently improves performance after intake ${ }^{17}$ and has a substantial benefit on cognitive function. Our previous study indicated that the regular intake of matcha

Manuscript received 28 July 2020. Revision accepted 16 February 2021.

Address correspondence to: Yoshitake Baba, MS, Central Research Institute, ITO EN, LTD., 21 Mekami, Makinohara, Shizuoka 421-0516, Japan, E-mail: yoshi-baba@itoen.co.jp

(C) Yoshitake Baba, et al., 2021; Published by Mary Ann Liebert, Inc. This Open Access article is distributed under the terms of the Creative Commons Attribution Noncommercial License [CC-BY-NC] (http://creativecommons.org/licenses/by-nc/4.0/) which permits any noncommercial use, distribution, and reproduction in any medium, provided the original author(s) and the source are cited. may improve attention. ${ }^{18}$ However, in that study, subjects did not consume matcha on the day of the test, suggesting that the improvement in attention was not a transient effect of caffeine but involved other components of the tea. A further implication would be that the regular intake of the tea is also a factor responsible for the observed improvement in attention.

L-theanine has been previously reported to have a neuroprotective effect. Because it suppresses delayed neuronal cell death in the hippocampal Cornu Ammonis 1 area after transient ischemia, ${ }^{19}$ reduces excitotoxicity by suppressing the extracellular release of glutamate through inhibition of the glutamine transporter, ${ }^{20}$ and promotes neurogenesis, ${ }^{21}$ L-theanine can potentially reduce cognitive impairment. However, there are many uncertainties about the effects of L-theanine on human cognitive function.

The purpose of this study was to clarify whether the intake of L-theanine, which has a neuroprotective effect, affects the cognitive processes of attention, working memory, and executive function. In addition, to investigate whether the single response was associated with cognitive function after regular ingestion, we compared the results of a single-dose and regular ingestion.

\section{MATERIALS AND METHODS}

The study was conducted at the Tokyo Skytree Station Medical Clinic (Tokyo, Japan) and was approved by the Research Ethics Committee of Nihonbashi Egawa Clinic (Tokyo, Japan; Approval No.: food-18071704). The study was conducted 


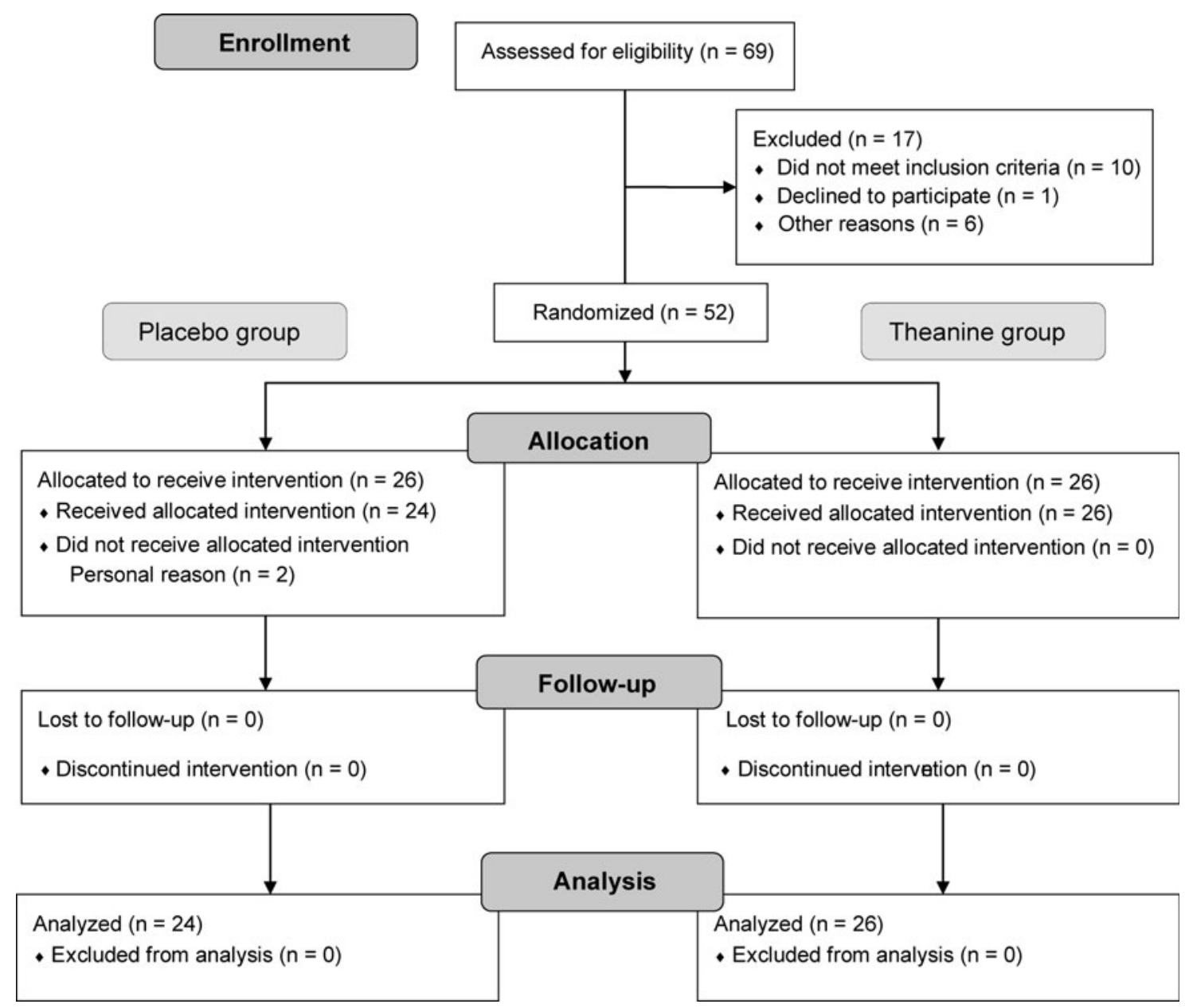

FIG. 1. Study flow diagram.

in accordance with the Declaration of Helsinki from August 8, 2018 to December 6, 2018. The study was registered with University Hospital Medical Information Network (Tokyo, Japan).

\section{Test food}

L-theanine (trade name: Suntheanine; Taiyo Kagaku Co., Ltd., Mie, Japan) was used as the test food. Suntheanine contains $\geq 98 \%$ L-theanine and was encapsulated into hard No. 1 porcine gelatin capsules and used for the test. A placebo was dispensed into the same type capsules as L-theanine, and corn starch was used as the excipient in both the theanine and placebo capsules. Each theanine capsule contained $100.6 \mathrm{mg}$ of L-theanine. The test food was manufactured at Sunsho Pharmaceutical Co., Ltd. (Shizuoka, Japan).

\section{Subjects}

Sixty-nine Japanese men and women certified as healthy by a physician based on hematological and biochemical blood test results and with self-assessed declined cognitive function were initially enrolled.

Of these, subjects with a Mini Mental State ExaminationJapanese version (MMSE-J) score $\geq 24$ were included, while those who had food allergies or were taking medication or undergoing treatment were excluded.
Table 1. Evaluation Scheme of the Clinical Trial

\begin{tabular}{lccc}
\hline & $\begin{array}{c}-1 \text { Week } \\
\text { (baseline) }\end{array}$ & $\begin{array}{c}\text { O Week } \\
\text { (single dose) }\end{array}$ & $\begin{array}{c}12 \\
\text { Weeks }\end{array}$ \\
\hline $\begin{array}{l}\text { Ingestion on test day } \\
\text { Medical interview }\end{array}$ & $\bullet$ & $\bullet$ & $\bullet$ \\
Height & $\bullet$ & $\bullet$ & $\bullet$ \\
Weight & $\bullet$ & $\bullet$ & $\bullet$ \\
Vital signs & $\bullet$ & $\bullet$ & $\bullet$ \\
Mlood sampling & $\bullet$ & & $\bullet$ \\
Cognitrax test & $\bullet$ & & $\bullet$
\end{tabular}

On the day of the test, evaluations marked with circles were implemented. Tests were carried out in the order listed in the table.

aBlood sampling was performed for hematologic tests (white blood cell count, red blood cell count, hemoglobin concentration, hematocrit, platelet count, mean corpuscular volume, mean corpuscular hemoglobin, and mean corpuscular hemoglobin concentration) and evaluation of biochemical blood parameters (total protein, triglycerides, total cholesterol, high-density lipoprotein cholesterol, low-density lipoprotein cholesterol, alkaline phosphatase, aspartate aminotransferase, alanine aminotransferase, gamma-glutamyl transpeptidase, lactate dehydrogenase, uric acid, urea nitrogen, total bilirubin, albumin, creatinine, fasting blood glucose, and glycated hemoglobin).

MMSE-J, Mini Mental State Examination-Japanese version. 
Table 2. Cognitrax Test Instructions

\begin{tabular}{|c|c|c|}
\hline Task & $\begin{array}{l}\text { Approximate time } \\
\text { required (min) }\end{array}$ & Overview \\
\hline VBM & 3 & First, memorize 15 words. Then, from the 30 words that appear at random, select the word you remembered \\
\hline VIM & 3 & Graphic version of the VBM test \\
\hline Finger Tapping & 2 & Quickly tap the key for $10 \mathrm{sec}$ with your index finger. Do this with both right and left hands. \\
\hline SDC & 4 & $\begin{array}{l}\text { Enter the number corresponding to the symbol while referring to the symbol-to-number correspondence } \\
\text { table. }\end{array}$ \\
\hline Stroop & 5 & $\begin{array}{l}\text { It consists of Parts } 1-3 \text {. Part } 1 \text { is pressing the key when the character appears. (Red, yellow, blue, and green } \\
\text { letters written in black are displayed.) Parts } 2 \text { and } 3 \text { display the letters red, yellow, blue, and green written } \\
\text { in red, yellow, blue, and green. Part } 2 \text { is pressing the key when matches, letters, and colors match. Part } 3 \\
\text { is pressing the key when letters and colors do not match. }\end{array}$ \\
\hline $\begin{array}{l}\text { Shifting } \\
\text { attention }\end{array}$ & 3 & $\begin{array}{l}\text { Follow the instructions on the screen and select the option that matches the color or shape. It is a } \\
\text { combination of red, blue, yellow, and green letters and colors. }\end{array}$ \\
\hline $\begin{array}{l}\text { Continuous } \\
\quad \text { Performance }\end{array}$ & 5 & Random letters of the alphabet are displayed one by one. Press the key only when B is displayed. \\
\hline $\begin{array}{l}\text { Perception } \\
\text { of Emotions }\end{array}$ & 2 & $\begin{array}{l}\text { The photo of a face and a word describing facial expression are displayed. The word used may be "calm," } \\
\text { "happy," "sad," or "angry." Press the key only if the photo and description match. We evaluated } \\
\text { positive emotions (calm and happiness), negative emotions (sadness and anger), and their sums. }\end{array}$ \\
\hline $\begin{array}{l}\text { Nonverbal } \\
\text { Reasoning }\end{array}$ & 3 & $\begin{array}{l}\text { One of the four sections is blank and three have symbols. Five examples are displayed on the screen. } \\
\text { Subjects look at the examples and choose the ones that are closest to the three symbols. }\end{array}$ \\
\hline $\begin{array}{l}\text { Four-Part } \\
\quad \text { Continuous } \\
\text { Performance }\end{array}$ & 7 & $\begin{array}{l}\text { It consists of Parts } 1-4 \text {. Part } 1 \text { is pressing the key when the figure appears. Part } 2 \text { is pressing the key when a } \\
\text { green circle appears. Part } 3 \text { is } 1 \text {-back task. Part } 4 \text { is } 2 \text {-back task. Shapes are displayed for Parts } 3 \text { and } 4 \\
\text { Shapes are a combination of circles, triangles, squares, and star shapes and red, blue, yellow, and green } \\
\text { colors. }\end{array}$ \\
\hline
\end{tabular}

SDC, symbol digit coding; VBM, verbal memory; VIM, visual memory.

The subjects participated in the study on their own initiative after receiving a full explanation of the study.

\section{Study design}

A double-blind, randomized placebo-controlled parallel group study was conducted. The primary end points were the results of MMSE-J and Cognitrax, and the secondary end points were blood levels of amyloid $\beta 1-40$ [A $\beta$ (1-40)], A $\beta$ $1-42[\mathrm{~A} \beta(1-42)]$, secreted form of amyloid- $\beta$ precursor protein $\alpha$ (sAPP $\alpha$ ), amyloid- $\beta$ precursor protein 770 (APP770), and brain-derived neurotrophic factor (BDNF). A computergenerated stratified randomized schema (Huma R\&D Corp., Tokyo, Japan; Contract Research Organization) was used to assign the subjects to either the placebo or the L-theanine group, with matching based on age, sex, and MMSE-J score. The study flow diagram are shown in Figure 1.

Subjects took one capsule per day of placebo or L-theanine for 12 weeks. They took the test food after breakfast. When they did not eat breakfast, they took the test food in the morning. Subjects were required to enter into the web input system (Huma R\&D Corp.), using a personal computer (PC), whether they had taken the test food. During the test period, the subjects were free to consume polyphenol-containing beverages (green tea, black tea, oolong tea, etc.), but subjects were restricted from taking any health foods, supplements, or medications that might affect cognitive function.

\section{Evaluation items}

The evaluation items are shown in Table 1. On the day of the single-dose study, the Cognitrax test was started $\sim 50 \mathrm{~min}$ after capsule intake. Except for taking the capsule before undergoing the tests, the tests were performed in the same order at week 12. Hematologic tests and biochemical blood parameter measurements were conducted at baseline and 12 weeks as a safety evaluation at SRL, Inc. (Tokyo, Japan).

Mini Mental State Examination-Japanese version. MMSE-J (Nihon Bunka Kagakusha Co., Ltd., Tokyo, Japan) is a Japanese version of MMSE, ${ }^{22}$ and its validity and test-

Table 3. Effects of L-Theanine on Biomarkers

\begin{tabular}{|c|c|c|c|c|}
\hline Group & $\mathrm{N}$ & $\begin{array}{l}-1 \text { Week } \\
\text { (baseline) }\end{array}$ & 12 Weeks & $\begin{array}{c}\text { Amount of change } \\
\text { from baseline }\end{array}$ \\
\hline \multicolumn{5}{|c|}{ Plasma A $\beta(1-40)(\mathrm{pg} / \mathrm{mL})$} \\
\hline Placebo & 22 & $219 \pm 56$ & $210 \pm 65$ & $-9.21 \pm 35$ \\
\hline Theanine & 26 & $243 \pm 175$ & $205 \pm 94$ & $-38.6 \pm 105$ \\
\hline \multicolumn{5}{|c|}{ Plasma $\mathrm{A} \beta(1-42)(\mathrm{pg} / \mathrm{mL})$} \\
\hline Placebo & 3 & $11.6 \pm 5.8$ & $22.7 \pm 10.5$ & $11.2 \pm 9.4$ \\
\hline Theanine & 9 & $21.6 \pm 21$ & $46.0 \pm 59$ & $24.3 \pm 52$ \\
\hline \multicolumn{5}{|c|}{$\mathrm{A} \beta(1-42) / \mathrm{A} \beta(1-40)$} \\
\hline Placebo & 10 & $0.04 \pm 0.03$ & $0.09 \pm 0.04$ & $0.05 \pm 0.02$ \\
\hline Theanine & 12 & $0.08 \pm 0.06$ & $0.24 \pm 0.31$ & $0.16 \pm 0.27$ \\
\hline \multicolumn{5}{|c|}{ Plasma sAPP $\alpha(n g / m L)$} \\
\hline Placebo & 25 & $8.07 \pm 4.1$ & $9.82 \pm 3.1$ & $1.75 \pm 2.4$ \\
\hline Theanine & 22 & $8.38 \pm 3.3$ & $10.2 \pm 4.7$ & $1.80 \pm 4.7$ \\
\hline \multicolumn{5}{|c|}{ Plasma APP770 (ng/mL) } \\
\hline Placebo & 23 & $29.2 \pm 13$ & $28.9 \pm 9.1$ & $-0.32 \pm 8.5$ \\
\hline Theanine & 26 & $30.6 \pm 12$ & $28.6 \pm 10$ & $-1.95 \pm 11$ \\
\hline \multicolumn{5}{|c|}{ Serum BDNF (ng/mL) } \\
\hline Placebo & 24 & $18.2 \pm 14$ & $24.3 \pm 11$ & $6.07 \pm 18$ \\
\hline Theanine & 26 & $21.8 \pm 12$ & $20.5 \pm 12$ & $-1.30 \pm 18$ \\
\hline
\end{tabular}

Values are presented as mean \pm SD.

$\mathrm{A} \beta$, amyloid- $\beta$; APP770, $\mathrm{A} \beta$ precursor protein 770 ; $\mathrm{BDNF}$, brain-derived neurotrophic factor; $\operatorname{sAPP} \alpha$, secreted form of $\mathrm{A} \beta$ precursor protein $\alpha$; $\mathrm{SD}$, standard deviation. 
retest reliability have been confirmed in Japan. ${ }^{23}$ The test consists of 11 items: time orientation, location orientation, memorization, attention and calculation, recall, naming, repetition, three-stage command, reading, writing, and copying, and it is evaluated with the total score. Two tests of attention and calculation were used: the backward spelling task and the serial sevens task, respectively. The score for the backward spelling task was used for allocation of subjects into the placebo or theanine group. ${ }^{22,23}$

Cognitrax test. Cognitrax ${ }^{24}$ is a test to evaluate cognitive function, developed by the U.S. company CNS Vital Signs (Morrisville, NC, USA). It comprises 10 test items with accompanying instructions. It measures both reaction time and number of responses. Reaction time is measured in milliseconds. The test items were ordered as follows: verbal memory (VBM), visual memory (VIM), finger tapping test (FTT), symbol digit coding (SDC), Stroop test (ST), shifting attention test (SAT), continuous performance test (CPT), perception of emotions test (POET), nonverbal reasoning test (NVRT), four-part CPT (FPCPT), VBM, and VIM. These items assess various cognitive functions-VBM and VIM assess memory; ST, SAT, CPT, and FPCPT Parts 1 and 2 assess attention; POET assesses facial expression recognition; FPCPT Parts 3 and 4 assess working memory; SDC and NVRT assess visual information processing; and FTT assesses motor function.

The first VBM and VIM performed are indicative of immediate memory, while the last is indicative of delayed memory. There were $\sim 50 \mathrm{~min}$ between the first-performed VBM and VIM and the last-performed VBM and VIM. Details of the test are shown in Table 2.

Biomarkers related to dementia. On the day of the test, the subjects were restricted from eating from $6 \mathrm{~h}$ before arriving at the hospital until the completion of the test.

Table 4. Performance on Attention Tasks

\begin{tabular}{|c|c|c|c|c|c|}
\hline Task & & Group & -1 Week (baseline) & 0 Week (single dose) & 12 Weeks \\
\hline \multirow[t]{2}{*}{ ST (Part 1) } & \multirow[t]{2}{*}{ Simple reaction time $(\mathrm{A})$} & Placebo & $411 \pm 145$ & $365 \pm 62.0$ & $337 \pm 43.8$ \\
\hline & & Theanine & $378 \pm 138$ & $337 \pm 84.0^{*}$ & $328 \pm 59.6$ \\
\hline \multirow[t]{2}{*}{ (Part 2) } & \multirow[t]{2}{*}{ Complex reaction time correct $(\mathrm{B})$} & Placebo & $734 \pm 124$ & $706 \pm 133$ & $679 \pm 80.1$ \\
\hline & & Theanine & $706 \pm 122$ & $667 \pm 97.8$ & $650 \pm 70.1$ \\
\hline \multirow[t]{8}{*}{ (Part 3) } & \multirow[t]{2}{*}{ Stroop reaction time correct $(\mathrm{C})$} & Placebo & $841 \pm 129$ & $809 \pm 98.2$ & $788 \pm 91.1$ \\
\hline & & Theanine & $802 \pm 121$ & $761 \pm 120$ & $754 \pm 106$ \\
\hline & \multirow[t]{2}{*}{ Stroop commission errors } & Placebo & $1.23 \pm 1.6$ & $0.96 \pm 1.0$ & $0.83 \pm 1.1$ \\
\hline & & Theanine & $0.73 \pm 0.96$ & $0.69 \pm 1.0$ & $0.77 \pm 0.76$ \\
\hline & \multirow[t]{2}{*}{$(\mathrm{C} / \mathrm{B}) \times 100$} & Placebo & $115 \pm 13$ & $116 \pm 14$ & $117 \pm 13$ \\
\hline & & Theanine & $115 \pm 14$ & $115 \pm 12$ & $116 \pm 10$ \\
\hline & \multirow[t]{2}{*}{$(\mathrm{A} / \mathrm{B}) \times 100$} & Placebo & $55.4 \pm 14$ & $52.2 \pm 7.2$ & $50.2 \pm 7.9$ \\
\hline & & Theanine & $52.9 \pm 11$ & $50.3 \pm 7.4$ & $50.4 \pm 7.0$ \\
\hline \multirow[t]{6}{*}{ SAT } & \multirow[t]{2}{*}{ Correct responses } & Placebo & $41.0 \pm 8.3$ & $46.3 \pm 6.8$ & $46.8 \pm 7.4$ \\
\hline & & Theanine & $45.0 \pm 8.0$ & $48.6 \pm 5.0$ & $50.2 \pm 5.4$ \\
\hline & \multirow[t]{2}{*}{ Errors } & Placebo & $5.7 \pm 5.0$ & $3.9 \pm 4.0$ & $3.8 \pm 4.0$ \\
\hline & & Theanine & $4.7 \pm 3.6$ & $4.0 \pm 2.4$ & $3.3 \pm 2.0$ \\
\hline & \multirow[t]{2}{*}{ Correct reaction time } & Placebo & $1266 \pm 144$ & $1151 \pm 121$ & $1144 \pm 163$ \\
\hline & & Theanine & $1167 \pm 157$ & $1067 \pm 132$ & $1045 \pm 134$ \\
\hline \multirow{8}{*}{$\mathrm{CPT}$} & \multirow{2}{*}{ Correct responses } & Placebo & $38.8 \pm 2.3$ & $39.5 \pm 0.8$ & $39.7 \pm 0.6$ \\
\hline & & Theanine & $39.6 \pm 1.4$ & $39.8 \pm 0.5$ & $39.7 \pm 1.0$ \\
\hline & \multirow[t]{2}{*}{ Omission errors } & Placebo & $1.15 \pm 2.3$ & $0.46 \pm 0.81$ & $0.29 \pm 0.62$ \\
\hline & & Theanine & $0.38 \pm 1.4$ & $0.15 \pm 0.46$ & $0.31 \pm 0.97$ \\
\hline & \multirow[t]{2}{*}{ Commission errors } & Placebo & $0.54 \pm 0.95$ & $0.38 \pm 0.75$ & $0.29 \pm 0.55$ \\
\hline & & Theanine & $0.15 \pm 0.46$ & $0.15 \pm 0.37$ & $0.27 \pm 0.45$ \\
\hline & \multirow[t]{2}{*}{ Choice reaction time correct } & Placebo & $511 \pm 50.7$ & $500 \pm 43.8$ & $493 \pm 42.1$ \\
\hline & & Theanine & $492 \pm 80.4$ & $483 \pm 72.1$ & $474 \pm 47.7$ \\
\hline \multirow[t]{2}{*}{ FPCPT (Part 1) } & \multirow[t]{2}{*}{ Average correct response time } & Placebo & $403 \pm 91$ & $394 \pm 100$ & $359 \pm 48$ \\
\hline & & Theanine & $409 \pm 132$ & $359 \pm 62$ & $347 \pm 53$ \\
\hline \multirow[t]{10}{*}{ (Part 2) } & \multirow[t]{2}{*}{ Correct responses } & Placebo & $5.7 \pm 1.1$ & $5.9 \pm 0.3$ & $5.7 \pm 1.2$ \\
\hline & & Theanine & $5.8 \pm 0.8$ & $6.0 \pm 0.2$ & $5.8 \pm 1.2$ \\
\hline & \multirow{2}{*}{ Average correct response time } & Placebo & $486 \pm 62$ & $461 \pm 50$ & $440 \pm 105$ \\
\hline & & Theanine & $476 \pm 95$ & $440 \pm 75$ & $420 \pm 96$ \\
\hline & \multirow[t]{2}{*}{ Incorrect responses } & Placebo & $0.38 \pm 0.75$ & $0.15 \pm 0.37$ & $0.42 \pm 1.1$ \\
\hline & & Theanine & $0.23 \pm 0.86$ & $0.15 \pm 0.61$ & $0.04 \pm 0.20$ \\
\hline & \multirow[t]{2}{*}{ Average incorrect response time } & Placebo & $144 \pm 253$ & $68.3 \pm 171$ & $74.3 \pm 175$ \\
\hline & & Theanine & $36.7 \pm 134$ & $31.6 \pm 117$ & $16.7 \pm 85$ \\
\hline & \multirow{2}{*}{ Omission errors } & Placebo & $0.31 \pm 1.1$ & $0.08 \pm 0.27$ & $0.29 \pm 1.2$ \\
\hline & & Theanine & $0.19 \pm 0.80$ & $0.04 \pm 0.20$ & $0.23 \pm 1.2$ \\
\hline
\end{tabular}

Values are presented as mean $\pm \mathrm{SD}$.

$* P<.05 / 3=0.017$ versus placebo group. $P$ values were calculated using the unpaired $t$-test or Mann-Whitney $\mathrm{U}$ test and Bonferroni correction. CPT, continuous performance test; FPCPT, four-part continuous performance test; SAT, shifting attention test; ST, stroop test. 
Serum blood collection tubes were used to estimate BDNF levels, while ethylenediamine tetra-acetate disodium tubes were used for $\mathrm{A} \beta(1-40), \mathrm{A} \beta(1-42), \mathrm{sAPP} \alpha$, and APP770 measurements. The blood was centrifuged at $3000 \mathrm{rpm}$ (Kokusan Co., Ltd., Tokyo, Japan, H-19Ra). The measurement was performed using kits with the following dilutions: the blood sample for $\mathrm{A} \beta(1-40)$ was diluted 20 times with human A $\beta(1-40)$ Full Length (FL) Assay Kit-IBL; the blood sample for $\mathrm{A} \beta(1-42)$ was diluted 4 times with human $\mathrm{A} \beta(1-42)$ (FL) Assay Kit-IBL; the blood sample for sAPP $\alpha$ was diluted four times with sAPP $\alpha$ (highly sensitive) Assay Kit-IBL; the blood sample for APP770 was diluted 50 times with human APP770 Assay Kit-IBL; and the blood sample for BDNF was diluted 20 times with human BDNF Enzyme-linked Immunosorbent Assay Kit (Quantikine-R\&D Systems). Any measured value below the kit range was excluded due to inaccuracy. The measurement was carried out by Skylight Biotech, Inc. (Akita, Japan). The results are shown in Table 3.

\section{Statistical analysis}

The values are presented as mean \pm standard deviation. Normality was tested using the Shapiro-Wilk test. The unpaired $t$-test or Mann-Whitney $U$ test was used to calculate $P$ values, with Bonferroni correction $(P<.05 / 3=0.017)$. This was performed at baseline, single-dose test, and 12 weeks. Data were analyzed using SAS 9.4 (SAS Institute, Inc., Cary, NC, USA).

\section{RESULTS}

The final analysis comprised 24 subjects in the placebo group (11 men and 13 women; average age,
$57.9 \pm 6.3$ years) and 26 subjects in the theanine group (12 men and 14 women; average age, $57.7 \pm 4.8$ years).

\section{MMSE-J (interactive test)}

There was no significant difference in MMSE-J scores between the theanine and placebo groups before and after the intervention (placebo group: before the intervention, $27.7 \pm 1.8$; after the intervention, $28.3 \pm 1.5$; theanine group: before the intervention, $27.7 \pm 1.4$; after the intervention, $28.0 \pm 1.6)$.

\section{Cognitrax test (PC-based cognitive function test)}

Attention task. In the single-dose study, ST (Part 1) reaction times were significantly lower in the theanine group than in the placebo group (Table 4). Therefore, a single dose of L-theanine was sufficient to improve attention.

Working memory tasks. In the single-dose FPCPT (Part 4), correct responses were significantly higher and omission errors were significantly lower in the theanine group than in the placebo group. In FPCPT (Part 4), compared to baseline, the theanine group had a significantly lower change in average incorrect response time in the single-dose study than the placebo group (Table 5). After single dose ingestion, L-theanine affected the quality of working memory, producing shorter reaction times and more correct answers.

L-theanine had no effect on performance in the memory tasks (Table 6), facial expression recognition task (Table 7),

Table 5. Performance on Working Memory Tasks

\begin{tabular}{|c|c|c|c|c|c|c|c|}
\hline \multirow[b]{2}{*}{ Task } & & \multirow[b]{2}{*}{ Group } & \multirow[b]{2}{*}{$\begin{array}{l}-1 \text { Week } \\
\text { (baseline) }\end{array}$} & \multirow[b]{2}{*}{$\begin{array}{c}0 \text { Week } \\
\text { (single dose) }\end{array}$} & \multirow[b]{2}{*}{12 Weeks } & \multicolumn{2}{|c|}{ Amount of change from baseline } \\
\hline & & & & & & $\begin{array}{c}\text { O Week } \\
\text { (single dose) }\end{array}$ & 12 Weeks \\
\hline \multirow{10}{*}{ FPCPT (Part 3) } & Correct responses & Placebo & $14.9 \pm 2.0$ & $15.2 \pm 1.2$ & $15.6 \pm 0.6$ & & \\
\hline & & Theanine & $14.8 \pm 2.3$ & $15.9 \pm 0.3$ & $15.7 \pm 0.8$ & & \\
\hline & Average correct response time & Placebo & $629 \pm 196$ & $577 \pm 89$ & $556 \pm 85$ & & \\
\hline & & Theanine & $594 \pm 135$ & $542 \pm 101$ & $535 \pm 84$ & & \\
\hline & Incorrect responses & Placebo & $0.15 \pm 0.61$ & $0.19 \pm 0.40$ & $0.04 \pm 0.20$ & & \\
\hline & & Theanine & $0.27 \pm 1.2$ & $0.00 \pm 0.00$ & $0.08 \pm 0.27$ & & \\
\hline & Average incorrect response time & Placebo & $66.6 \pm 236$ & $172 \pm 433$ & $32.5 \pm 159$ & & \\
\hline & & Theanine & $38.0 \pm 136$ & $0.0 \pm 0.0$ & $127 \pm 564$ & & \\
\hline & Omission errors & Placebo & $1.12 \pm 2.0$ & $0.77 \pm 1.2$ & $0.42 \pm 0.58$ & & \\
\hline & & Theanine & $1.15 \pm 2.3$ & $0.12 \pm 0.33$ & $0.27 \pm 0.83$ & & \\
\hline \multirow[t]{10}{*}{ (Part 4) } & Correct responses & Placebo & $12.0 \pm 2.3$ & $12.1 \pm 2.2$ & $12.5 \pm 2.6$ & $0.2 \pm 2.3$ & $0.8 \pm 2.7$ \\
\hline & & Theanine & $11.8 \pm 3.4$ & $13.4 \pm 2.8^{*}$ & $13.3 \pm 2.0$ & $1.6 \pm 2.5$ & $1.5 \pm 3.4$ \\
\hline & Average correct response time & Placebo & $698 \pm 117$ & $691 \pm 129$ & $659 \pm 111$ & & \\
\hline & & Theanine & $704 \pm 173$ & $676 \pm 162$ & $625 \pm 98$ & & \\
\hline & Incorrect responses & Placebo & $1.6 \pm 1.6$ & $1.6 \pm 1.2$ & $1.7 \pm 1.7$ & & \\
\hline & & Theanine & $1.6 \pm 1.9$ & $1.4 \pm 1.6$ & $1.5 \pm 1.4$ & & \\
\hline & Average incorrect response time & Placebo & $581 \pm 431$ & $769 \pm 448$ & $467 \pm 428$ & $188 \pm 497$ & $-91.0 \pm 448$ \\
\hline & & Theanine & $742 \pm 511$ & $584 \pm 504$ & $653 \pm 415$ & $-158 \pm 590^{*}$ & $-88.8 \pm 756$ \\
\hline & Omission errors & Placebo & $4.0 \pm 2.3$ & $3.9 \pm 2.2$ & $3.5 \pm 2.6$ & $-0.2 \pm 2.3$ & $-0.8 \pm 2.7$ \\
\hline & & Theanine & $4.2 \pm 3.4$ & $2.6 \pm 2.8^{*}$ & $2.7 \pm 2.0$ & $-1.6 \pm 2.5$ & $-1.5 \pm 3.4$ \\
\hline
\end{tabular}

Values are presented as mean $\pm \mathrm{SD}$.

$* P<.05 / 3=0.017$ versus placebo group. $P$ values were calculated using the Mann-Whitney $U$ test and Bonferroni correction. 
Table 6. Performance on Memory Tasks

\begin{tabular}{|c|c|c|c|c|c|}
\hline Task & & Group & -1 Week (baseline) & O Week (single dose) & 12 Weeks \\
\hline \multirow[t]{8}{*}{ VBM } & \multirow[t]{2}{*}{ Correct hits-immediate } & Placebo & $10.3 \pm 2.4$ & $11.1 \pm 1.9$ & $11.3 \pm 1.7$ \\
\hline & & Theanine & $10.2 \pm 2.0$ & $11.3 \pm 1.8$ & $11.4 \pm 1.3$ \\
\hline & \multirow{2}{*}{ Correct passes_-immediate } & Placebo & $14.7 \pm 0.6$ & $14.6 \pm 0.7$ & $14.4 \pm 1.2$ \\
\hline & & Theanine & $14.7 \pm 0.7$ & $14.5 \pm 0.9$ & $14.6 \pm 0.8$ \\
\hline & \multirow[t]{2}{*}{ Correct hits—delay } & Placebo & $8.8 \pm 3.5$ & $9.4 \pm 2.7$ & $10.5 \pm 2.3$ \\
\hline & & Theanine & $9.5 \pm 2.7$ & $10.4 \pm 2.0$ & $10.8 \pm 2.2$ \\
\hline & \multirow[t]{2}{*}{ Correct passes-delay } & Placebo & $14.5 \pm 0.9$ & $14.0 \pm 1.2$ & $14.2 \pm 1.5$ \\
\hline & & Theanine & $14.0 \pm 1.5$ & $13.4 \pm 1.9$ & $13.8 \pm 2.3$ \\
\hline \multirow[t]{8}{*}{ VIM } & \multirow[t]{2}{*}{ Correct hits-immediate } & Placebo & $10.1 \pm 2.0$ & $10.1 \pm 2.1$ & $10.3 \pm 1.8$ \\
\hline & & Theanine & $9.5 \pm 2.6$ & $9.9 \pm 2.0$ & $9.4 \pm 2.5$ \\
\hline & \multirow[t]{2}{*}{ Correct passes_immediate } & Placebo & $13.0 \pm 1.5$ & $12.4 \pm 2.2$ & $12.5 \pm 1.8$ \\
\hline & & Theanine & $12.8 \pm 2.3$ & $12.4 \pm 1.7$ & $12.6 \pm 2.3$ \\
\hline & \multirow[t]{2}{*}{ Correct hits—delay } & Placebo & $9.0 \pm 2.9$ & $9.9 \pm 2.1$ & $9.8 \pm 2.2$ \\
\hline & & Theanine & $9.3 \pm 2.9$ & $9.2 \pm 2.5$ & $9.0 \pm 2.5$ \\
\hline & \multirow{2}{*}{ Correct passes-delay } & Placebo & $11.5 \pm 2.5$ & $10.9 \pm 2.6$ & $10.3 \pm 2.6$ \\
\hline & & Theanine & $11.5 \pm 2.8$ & $11.7 \pm 2.5$ & $10.9 \pm 3.1$ \\
\hline
\end{tabular}

Values are presented as mean $\pm \mathrm{SD}$.

visual information processing tasks (Table 8), and motor function (Table 9) either immediately or following chronic ingestion.

\section{Blood biomarkers}

No significant difference was observed between the placebo and theanine groups (Table 3 ).

\section{DISCUSSION}

This study evaluated the effects of L-theanine on cognitive function using the Cognitrax test performed on a PC. We investigated whether the regular intake of theanine for 12 weeks could improve attentional function and which cognitive functions a single dose of theanine would affect.
A cup of green tea contains about $25 \mathrm{mg}$ of theanine. ${ }^{25}$ Kuriyama et al. reported that people who drink green tea have less cognitive dysfunction. ${ }^{9}$ In the previous report, the amount of theanine that led to an improvement in attentional function was $50.3 \mathrm{mg}$. In this study, the dose of theanine was set at $100.6 \mathrm{mg}$ for the purpose of clearly showing the effect of theanine alone. A single dose of L-theanine reduced reaction time in the attention task and increased correct answers and decreased the number of omission errors in the working memory task. This suggests that L-theanine may improve working memory and executive function based on the improvement in attention.

It is interesting that caffeine, ${ }^{26}$ which acts as a stimulant for neural activity, and L-theanine, ${ }^{27}$ which acts as a depressant, are both contained in green tea. Several studies have reported synergistic effects of caffeine and L-theanine on cognition and mood, ${ }^{28}$ as well as on tasks related to

Table 7. Performance on the Facial Expression Recognition Task

\begin{tabular}{|c|c|c|c|c|c|}
\hline Task & & Group & -1 Week (baseline) & o Week (single dose) & 12 Weeks \\
\hline \multirow[t]{8}{*}{ POET } & \multirow[t]{2}{*}{ Correct responses } & Placebo & $10.4 \pm 1.5$ & $10.1 \pm 1.8$ & $10.1 \pm 1.3$ \\
\hline & & Theanine & $10.5 \pm 1.3$ & $10.5 \pm 1.4$ & $10.7 \pm 1.1$ \\
\hline & \multirow[t]{2}{*}{ Average correct reaction time } & Placebo & $1247 \pm 151$ & $1242 \pm 218$ & $1265 \pm 159$ \\
\hline & & Theanine & $1197 \pm 165$ & $1143 \pm 158$ & $1180 \pm 158$ \\
\hline & \multirow[t]{2}{*}{ Omission errors } & Placebo & $1.6 \pm 1.5$ & $1.9 \pm 1.8$ & $1.9 \pm 1.3$ \\
\hline & & Theanine & $1.5 \pm 1.3$ & $1.5 \pm 1.4$ & $1.3 \pm 1.1$ \\
\hline & \multirow[t]{2}{*}{ Commission errors } & Placebo & $3.1 \pm 2.3$ & $3.1 \pm 2.4$ & $3.1 \pm 1.8$ \\
\hline & & Theanine & $3.7 \pm 2.8$ & $4.2 \pm 3.2$ & $3.7 \pm 2.8$ \\
\hline \multirow{4}{*}{ Positive emotions } & \multirow[t]{2}{*}{ Correct hits } & Placebo & $5.5 \pm 0.8$ & $5.4 \pm 0.7$ & $5.2 \pm 1.0$ \\
\hline & & Theanine & $5.3 \pm 0.8$ & $5.6 \pm 0.7$ & $5.4 \pm 0.9$ \\
\hline & \multirow{2}{*}{ Reaction time } & Placebo & $1239 \pm 165$ & $1232 \pm 225$ & $1232 \pm 208$ \\
\hline & & Theanine & $1207 \pm 223$ & $1158 \pm 173$ & $1167 \pm 185$ \\
\hline \multirow[t]{4}{*}{ Negative emotions } & \multirow[t]{2}{*}{ Correct hits } & Placebo & $4.8 \pm 1.2$ & $4.7 \pm 1.4$ & $4.9 \pm 1.0$ \\
\hline & & Theanine & $5.2 \pm 1.0$ & $4.9 \pm 1.1$ & $5.3 \pm 0.7$ \\
\hline & \multirow[t]{2}{*}{ Reaction time } & Placebo & $1266 \pm 206$ & $1239 \pm 246$ & $1285 \pm 187$ \\
\hline & & Theanine & $1186 \pm 198$ & $1121 \pm 162$ & $1191 \pm 195$ \\
\hline
\end{tabular}

Values are presented as mean $\pm \mathrm{SD}$. 
Table 8. Performance on Visual Information Processing Tasks

\begin{tabular}{|c|c|c|c|c|c|}
\hline Task & & & -1 Week (baseline) & o Week (single dose) & 12 Weeks \\
\hline \multirow[t]{4}{*}{ SDC } & \multirow[t]{2}{*}{ Correct responses } & Placebo & $54.8 \pm 8.7$ & $59.3 \pm 7.8$ & $59.3 \pm 9.8$ \\
\hline & & Theanine & $58.3 \pm 6.5$ & $61.5 \pm 6.8$ & $63.0 \pm 6.0$ \\
\hline & \multirow[t]{2}{*}{ Errors } & Placebo & $0.77 \pm 0.95$ & $0.62 \pm 1.1$ & $1.29 \pm 1.5$ \\
\hline & & Theanine & $0.62 \pm 0.85$ & $0.96 \pm 1.2$ & $1.04 \pm 1.3$ \\
\hline \multirow[t]{8}{*}{ NVRT } & \multirow{2}{*}{ Correct responses } & Placebo & $9.3 \pm 1.7$ & $9.2 \pm 2.3$ & $8.9 \pm 2.4$ \\
\hline & & Theanine & $9.9 \pm 1.9$ & $9.4 \pm 2.4$ & $10.3 \pm 1.5$ \\
\hline & \multirow{2}{*}{ Average correct reaction time } & Placebo & $4204 \pm 1055$ & $4019 \pm 1025$ & $3559 \pm 837$ \\
\hline & & Theanine & $4300 \pm 1083$ & $4098 \pm 1251$ & $4034 \pm 597$ \\
\hline & \multirow[t]{2}{*}{ Commission errors } & Placebo & $4.9 \pm 2.1$ & $5.5 \pm 2.5$ & $5.9 \pm 2.4$ \\
\hline & & Theanine & $4.7 \pm 2.0$ & $5.4 \pm 2.3$ & $4.5 \pm 1.6$ \\
\hline & \multirow[t]{2}{*}{ Omission errors } & Placebo & $0.73 \pm 0.87$ & $0.35 \pm 0.69$ & $0.17 \pm 0.38$ \\
\hline & & Theanine & $0.38 \pm 0.70$ & $0.15 \pm 0.37$ & $0.23 \pm 0.59$ \\
\hline
\end{tabular}

Values are presented as mean $\pm \mathrm{SD}$.

attentional function. ${ }^{18}$ Our results suggest that L-theanine by itself improves working memory. It remains possible that the improvement in attention, as described previously, ${ }^{18}$ may have contributed to this effect. In this study, after 12 weeks of regular ingestion, theanine had no effect on the processes related to attentional function as previously reported, even though our subjects had ages and MMSE scores similar to those of subjects in previous studies. The difference in this effect may have been due to the combined effect of caffeine and theanine or catechin and theanine, but details of such interactions are unknown, and further investigation is required.

Studies that explored brain activity have previously reported that L-theanine intake increases $\alpha$-wave activity. ${ }^{29,30}$ A study by Gomez-Ramirez et al. ${ }^{31}$ found that subjects who ingested $250 \mathrm{mg}$ of L-theanine had increased $\alpha$-wave activity for the attention task to be performed. Furthermore, a study that used a visuospatial task also showed that the intake of $250 \mathrm{mg}$ of L-theanine contributed to sustained attention. ${ }^{32}$ Although increased $\alpha$-wave activity does not simply indicate wakefulness in the brain, L-theanine may affect selective or sustained attentional function. In this study, a significant decrease in reaction time was observed for ST (Part 1), which indicates sustained attention and provides further support for the effects of L-theanine on attentional function. It will therefore be necessary to use neurophysiological techniques to study how the regular intake of theanine affects nervous system activity.

Table 9. Performance on Motor Function Tasks

\begin{tabular}{|c|c|c|c|c|c|}
\hline Task & & Group & $\begin{array}{l}-1 \text { Week } \\
\text { (baseline) }\end{array}$ & $\begin{array}{c}\text { O Week } \\
\text { (single dose) }\end{array}$ & 12 Weeh \\
\hline \multirow[t]{4}{*}{ FTT } & \multirow{2}{*}{$\begin{array}{r}\text { Right taps } \\
\text { average }\end{array}$} & Placebo & $54.7 \pm 8.2$ & $55.5 \pm 7.3$ & $56.9 \pm 7.2$ \\
\hline & & Theanine & $55.9 \pm 8.2$ & $58.7 \pm 5.4$ & $59.1 \pm 7$ \\
\hline & \multirow{2}{*}{$\begin{array}{l}\text { Left taps } \\
\text { average }\end{array}$} & Placebo & $53.2 \pm 8.5$ & $53.0 \pm 8.1$ & $53.7 \pm 7$ \\
\hline & & Theanine & $52.4 \pm 6.6$ & $54.0 \pm 5.7$ & $54.9 \pm 6$ \\
\hline
\end{tabular}

Values are presented as mean \pm SD.

FTT, finger tapping test.
According to a study by Baddeley, ${ }^{33}$ working memory is composed of three factors: a phonological loop for language information processing, a visuospatial sketch pad for visuospatial information processing, an episodic buffer, and a central executive system that integrates the other three parts. The central executive system is considered to be related to attention control. The effects observed in the twoback task (FPCPT, Part 4) are the results of L-theanine contributing to the improvement of working memory through distribution of attention resources and movement of focus of attention, that is, efficient shifting. Based on this observation, it is also necessary to examine brain activity during task execution using functional magnetic resonance imaging.

Because attention and working memory are closely related ${ }^{34}$ it is difficult to consider them separately. It is therefore necessary to examine, in more detail, attentional function and working memory, which were found to be improved by L-theanine in this study.

The limitations of this study involve subject age and cognitive function status. This study was conducted in middle-aged and older subjects who were aware of a decline in their cognitive function. Previous studies tested elderly people, including those who had mild cognitive impairment $^{35}$ or vascular dementia, ${ }^{36}$ to verify whether green tea powder could improve cognitive function. In the future, a comparative study on the preventive or restorative effects of L-theanine in younger adults, the aged, and patients with mild cognitive impairment must also be considered. We also could not explain why regular administration of L-theanine was necessary, as is accepted for epidemiological studies. Future studies are therefore required to investigate the differential effects of single dose and daily intake of L-theanine on brain structure and cognitive function.

\section{ACKNOWLEDGMENTS}

The authors gratefully acknowledge the individuals who participated in the study and the clinical research coordinator, Huma R\&D Corp. The authors thank Editage for English language editing. 


\section{AUTHOR DISCLOSURE STATEMENT}

ITO EN, Ltd. covered the testing costs and provided the test food as the study sponsor. Huma R\&D Corp., Contract Research Organization, conducted subject recruitment, selection, allocation, observation, and data collection. Kureha Special Laboratory Co., Ltd. conducted statistical analysis. T.K. was the principal investigator for this study and was contracted by Huma R\&D to conduct the study. The study was performed by a third party. The remaining authors report that no competing financial interests exist.

\section{FUNDING INFORMATION}

The authors have no conflicts of interest directly relevant to the content of this article.

\section{REFERENCES}

1. Sakato Y: Studies on the chemical constituents of tea; III. A new amide theanine. Nippon Nogeikagaku Kaishi (Japanese) 1949; 23:262-267.

2. Casimir J, Jadot J, Renard M: Separation and characterization of N-ethyl-gamma-glutamine from Xerocomus badius. Biochim Biophys Acta 1960;39:462-468.

3. Goto T, Yoshida Y, Amano I, Horie H: Chemical composition of commercially available Japanese green tea. Foods Food Ingredients J Jpn 1996;170:46-51.

4. Yoneda Y, Kuramoto N, Kawada K: The role of glutamine in neurogenesis promoted by the green tea amino acid theanine in neural progenitor cells for brain health. Neurochem Int 2019;129: 104505 .

5. Tamano H, Fukura K, Suzuki M, Sakamoto K, Yokogoshi H, Takeda A: Preventive effect of theanine intake on stress-induced impairments of hippocamapal long-term potentiation and recognition memory. Brain Res Bull 2013;95:1-6.

6. Unno K, Fujitani K, Takamori N, et al.: Theanine intake improves the shortened lifespan, cognitive dysfunction and behavioural depression that are induced by chronic psychosocial stress in mice. Free Radic Res 2011;45:966-974.

7. Nguyen BT, Sharma N, Shin EJ, et al.: Theanine attenuates memory impairments induced by klotho gene depletion in mice. Food Funct 2019;10:325-332.

8. Noguchi-Shinohara M, Sohshi Y, Dohmoto C, et al.: Consumption of green tea, but not black tea or coffee, is associated with reduced risk of cognitive decline. PLoS One 2014;9:e96013.

9. Kuriyama S, Hozawa A, Ohmori K, et al.: Green tea consumption and cognitive function: A cross-sectional study from the Tsurugaya Project. Am J Clin Nutr 2006;83:355-361.

10. Sekita A, Ninomiya T, Tanizaki Y, et al:: Trends in prevalence of Alzheimer's disease and vascular dementia in a Japanese community: The Hisayama Study. Acta Psychiatr Scand 2010;122:319-325.

11. Ninomiya T: Japanese legacy cohort studies: The Hisayama Study. J Epidemiol 2018;28:444-451.

12. Lieberman HR, Wurtman RJ, Emde GG, Roberts C, Coviella ILG: The effects of low doses of caffeine on human performance and mood. Psychopharmacology (Berl) 1987;92:308-312.

13. Smit HJ, Rogers PJ: Effects of low doses of caffeine on cognitive performance, mood and thirst in low and higher caffeine consumers. Psychopharmacology (Berl) 2000;152:167-173.
14. Takeda A, Sakamoto K, Tamano H, et al:: Facilitated neurogenesis in the developing hippocampus after intake of theanine, an amino acid in tea leaves, and object recognition memory. Cell Mol Neurobiol 2011;31:1079-1088.

15. Chang X, Rong C, Chen Y, et al.: (-)-Epigallocatechin-3-gallate attenuates cognitive deterioration in Alzheimer's disease model mice by upregulating neprilysin expression. Exp Cell Res 2015; 334:136-145.

16. Gundimeda U, McNeil TH, Fan TK, et al.: Green tea catechins potentiate the neuritogenic action of brain-derived neurotrophic factor: Role of 67-kDa laminin receptor and hydrogen peroxide. Biochem Biophys Res Commun 2014;445:218-224.

17. Addicot MA, Laurienti PJ: A comparison of the effects of caffeine following abstinence and normal caffeine use. Psychopharmacology (Berl) 2009;207:423-431.

18. Baba Y, Takihara T, Sagesaka Y, Kaneko T: Effects of a daily intake of matcha on cognitive function in middle-aged and older subjects-A placebo-controlled, randomized, double-blind, parallel-group study. Jpn Pharmacol Ther 2019;47:16891702 .

19. Kakuda T, Yanase H, Utsunomiya K, Nozawa A, Unno T, Kataoka K: Protective effect of $\gamma$-glutamylethylamide (theanine) on ischemic delayed neuronal death in gerbils. Neurosci Lett 2000;289:189-192.

20. Kakuda T, Nozawa A, Sugimoto A, Niino H: Inhibition by theanine of binding of [3H]AMPA, [3H]Kainate, and [3H]MDL 105,519 to glutamate receptors. Biosci Biotechnol Biochem 2002; 66:2683-2686.

21. Ogura M, Kakuda T, Takarada T, et al:: Promotion of both proliferation and neuronal differentiation in pluripotent P19 cells with stable overexpression of the glutamine transporter slc38a1. PLoS One 2012;7:e48270.

22. Folstein MF, Folstein SE, McHugh PR: 'Mini-mental state': A practical method for grading the cognitive state of patients for the clinician. J Psychiatr Res 1975;12:189-198.

23. Sugishita M, Hemmi I, Tomoko T: Reexamination of the validity and reliability of the Japanese version of the Mini-Mental State Examination (MMSE-J). Jpn J Cogn Neurosci 2016;18: 168-183.

24. Gualtieri CT, Johnson LG: Reliability and validity of a computerized neurocognitive test battery, CNS Vital Signs. Arch Clin Neuropsychol 2006;21:623-643.

25. Keenan EK, Finnie MDA, Jones PS, Rogers PJ, Priestley CM: How much theanine in a cup of tea? Effects of tea type and method of preparation. Food Chem 2011;125:588-594.

26. Huang ZL, Qu WM, Eguchi N, et al.: Adenosine A2A, but not $\mathrm{A} 1$, receptors mediate the arousal effect of caffeine. Nat Neurosci 2005;8:858-859.

27. Kakuda T, Nozawa A, Unno T, Okamura N, Okai O: Inhibiting effects of theanine on caffeine stimulation evaluated by EEG in the rat. Biosci Biotechnol Biochem 2000;64:287-293.

28. Haskell CF, Kennedy DO, Milne AL, Wesnes KA, Scholey AB: The effects of L-theanine, caffeine and their combination on cognition and mood. Biol Psychol 2008;77:113-122.

29. Kobayashi K, Nagato Y, Aoi N, et al:: Effects of L-Theanine on the release of alpha-brain waves in human volunteers. J Agric Chem Soc Jpn 1998;72:153-157.

30. Nobre AC, Rao A, Owen GN: L-theanine, a natural constituent in tea, and its effect on mental state. Asia Pac J Clin Nutr 2008;17: $167-168$. 
31. Gomez-Ramirez M, Higgins BA, Rycroft JA, et al:: The deployment of intersensory selective attention: A high-density electrical mapping study of the effects of theanine. Clin Neuropharmacol 2007;30:25-38.

32. Gomez-Ramirez M, Kelly SP, Montesi JL, Foxe JJ: The effects of L-theanine on alpha-band oscillatory brain activity during a visuo-spatial attention task. Brain Topogr 2009;22:44-51.

33. Baddeley A: The episodic buffer: A new component of working memory? Trends Cogn Sci 2000;4:417-423.
34. Hideya K: Neuroscience of working memory. Jpn J Geriatr Psychiatry 2014;25:504-508.

35. Ide $\mathrm{K}$, Yamada $\mathrm{H}$, Takuma $\mathrm{N}$, et al.: Green tea consumption affects cognitive dysfunction in the elderly: A pilot study. Nutrients 2014;6:4032-4042.

36. Kataoka Y, Utsunomiya K, Kimbara N, Fukushima K, Mori T, Shiba J: Preventive effect of green tea containing theanine at a high concentration on dementia in aged volunteers. J Jpn Mibyou Syst Assoc [In Japanese] 2009;15:17-23. 